\title{
Matrix metalloproteinases 2 and 9 (gelatinases A and B) expression in malignant mesothelioma and benign pleura
}

\author{
JG Edwards',2, J McLaren ${ }^{3}$, JL Jones ${ }^{4}$, DA Waller², and KJ O'Byrne ${ }^{*, 1}$ \\ 'University Department of Medical Oncology, Osborne Building, Leicester Royal Infirmary, Leicester LEI 5WW, UK; ${ }^{2}$ Department of Respiratory Medicine \\ and Thoracic Surgery, Glenfield Hospital NHS Trust, Groby Road, Leicester LE3 9QP, UK; ${ }^{3}$ Department of Obstetrics and Gynaecology, University of \\ Leicester, Robert Kilpatrick Building, Leicester Royal Infirmary, Leicester LEI 5WW, UK; and ${ }^{4}$ Department of Pathology, University of Leicester, Robert \\ Kilpatrick Building, Leicester Royal Infirmary, Leicester LEI 5WW, UK
}

\begin{abstract}
Matrix metalloproteinases (MMPs), in particular the gelatinases (MMP-2 and -9), play a significant role in tumour invasion and angiogenesis. The expression and activities of MMPs have not been characterised in malignant mesothelioma (MM) tumour samples. In a prospective study, gelatinase activity was evaluated in homogenised supernatants of snap frozen MM ( $n=35)$, inflamed pleura (IP, $n=12)$ and uninflammed pleura (UP, $n=14)$ tissue specimens by semiquantitative gelatin zymography. Matrix metalloproteinases were correlated with clinicopathological factors and with survival using Kaplan-Meier and Cox proportional hazard models. In MM, pro- and active MMP-2 levels were significantly greater than for MMP-9 $(P=0.006, P<0.00 \mathrm{I})$. Active MMP-2 was significantly greater in MM than in UP $(P=0.04)$. MMP-2 activity was equivalent between IP and MM, but both pro- and active MMP-9 activities were greater in $\mathbb{P}(P=0.02, P=0.009)$. While there were trends towards poor survival with increasing total and pro-MMP-2 activity $(P=0.08)$ in univariate analysis, they were both independent poor prognostic factors in multivariate analysis in conjunction with weight loss (pro-MMP-2 $P=0.03$, total MMP-2 $P=0.04$ ). Total and pro-MMP-2 also contributed to the Cancer and Leukemia Group B prognostic groups. MMP-9 activities were not prognostic. Matrix metalloproteinases, and in particular MMP-2, the most abundant gelatinase, may play an important role in MM tumour growth and metastasis. Agents that reduce MMP synthesis and/or activity may have a role to play in the management of $M M$.

British Journal of Cancer (2003) 88, I553- 1559. doi: I0.1038/sj.bjc.6600920 www.bjcancer.com

(c) 2003 Cancer Research UK
\end{abstract}

Keywords: malignant mesothelioma; matrix metalloproteinases; prognosis

Malignant mesothelioma (MM) is an aggressive and invariably fatal serosal tumour of increasing incidence usually associated with asbestos exposure. Median survival in the UK is less than 6 months from the date of diagnosis (Edwards et al, 2000). Malignant mesothelioma is characterised by rapid progression and invasion of intrathoracic structures. Although commonly perceived as a tumour that rarely metastasises, nodal disease is present in about $40 \%$ of patients undergoing extrapleural pneumonectomy (Sugarbaker and Norberto, 1998), while distant metastases are seen in at least $70 \%$ at the time of death (Rusch et al, 1991). Malignant mesothelioma responds poorly to conventional modes of therapy including surgery, chemotherapy and radiotherapy (Sterman et al, 1999). Staging by the conventional criteria of Tumour-NodesMetastasis (TNM) is difficult in MM: that proposed by the International Mesothelioma Interest Group (IMIG) is the most recent TNM staging system (Rusch, 1995). However, in a large series of patients managed by radical surgery and chemoradiotherapy, this staging system failed to stratify survival (Sugarbaker et al, 1999). For MM, prognostic scoring systems incorporating clinicopathological variables have been proposed by the European Organisation for Research and Treatment of Cancer (EORTC) (Curran et al, 1998) and the Cancer and

*Correspondence: Dr KJ O’Byrne; E-mail: ken.obyrne@uhl-tr.nhs.uk Received 6 September 2002; revised 17 February 2003; accepted 26 February 2003
Leukemia Group B (CALGB) (Herndon et al, 1998). These systems have been useful in predicting survival in our patient population (Edwards et al, 2000).

Novel prognostic factors, such as microvessel density (MVD), a marker of the intensity of angiogenesis, have been examined in MM. High MVD is associated with a poor outcome in this disease (Kumar-Singh et al, 1997; Edwards et al, 2001), in keeping with the results from similar studies in other solid tumours (Dickinson et al, 1994; Fox et al, 1994; Cox et al, 2000c). Furthermore, in other solid tumours, such as nonsmall cell lung cancer, novel biological staging systems are being developed, which contribute independently to TNM stage (Cox et al, 2000a; O'Byrne et al, 2001).

Proteolysis of the extracellular matrix and basement membrane, by proteases such as matrix metalloproteinases (MMPs), is a central part of tumour growth and metastasis. The stromal remodelling mediated by these enzymes also facilitates tumour angiogenesis. MMPs are a family of zinc-dependent enzymes, which are implicated in the growth of primary and secondary tumours (Cox et al, 1999). Overexpression of MMPs, in particular gelatinase A (MMP-2), gelatinase B (MMP-9) and stromelysin-3 (MMP-11), is related to tumour progression and metastasis in solid tumours including gastric (Schwartz, 1996), colon (Karakiulakis et al, 1997) and lung cancer (Cox et al, 2000b).

Reports using semiquantitative gelatin zymography have correlated MMP-2 and/or MMP-9 activity with survival and disease progression in several solid tumour types (Brown et al, 
1993b; Tokuraku et al, 1995; Ikebe et al, 1999; Papathoma et al, 2000; Lengyel et al, 2001; Di Nezza et al, 2002; Waas et al, 2002). The use of SDS in the buffers activates latent gelatinase isoforms, which enables assessment of both the latent (pro) and active bands of enzymatic activity. Although MMP expression has been described in MM cell lines (Harvey et al, 2000; Liu et al, 2001), the activity of MMPs has not been described in MM tumour samples. We have assessed, by gelatin zymography, the activities of MMP-2 and -9 in specimens of benign pleura and MM.

\section{MATERIALS AND METHODS}

\section{Patients and samples}

Patients referred to the regional Department of Cardiothoracic Surgery for surgical management of pleural diseases were identified prospectively. Patients were due to undergo surgery for biopsy, management of pleural effusion, empyema or pneumothorax or for palliative or radical surgery for malignant mesothelioma. Clinicopathological prognostic factors, including CALGB (Herndon et al, 1998) and EORTC (Curran et al, 1998) prognostic groups were recorded before surgery, as described previously (Edwards et al, 2000). For the patients undergoing radical surgery, the IMIG TNM pathological stage was derived.

Samples of MM, inflamed pleura (IP) or uninflammed, benign pleura (UP) were collected at surgery from consecutive patients. Surgery in MM patients $(n=35,23$ epithelioid, seven mixed cellularity, five sarcomatoid) was performed either for diagnostic biopsy or for symptom control. IP patients $(n=12)$ had empyema thoracis and underwent decortication of visceral pleura and/or parietal pleurectomy. UP specimens were taken from patients $(n=15)$ at the time of pleurectomy for primary spontaneous pneumothorax. Samples were assessed macroscopically and representative areas (e.g. tumour nodules) were processed as formalin-fixed, paraffin-embedded blocks for diagnostic evaluation, or snap frozen in liquid nitrogen and stored at $-80^{\circ} \mathrm{C}$ for zymography. Standard diagnostic immunohistochemistry was performed to confirm the diagnosis, using antibodies including CEA, BerEP4, AUA-1 and HBME1, where appropriate. Following surgery, the detailed histopathological report and diagnostic slides were reviewed by a second pathologist to confirm the diagnosis.

\section{Gelatin zymography}

Samples were homogenised mechanically at $4^{\circ} \mathrm{C}$ in a zymography homogenisation buffer (containing the protease inhibitor phenylmethylsulphonyl fluoride (PMSF, Sigma-Aldrich, Poole, UK, at $0.1 \mathrm{mM}$ ), centrifuged and the supernatant refrozen. Protein concentrations were derived with a Bradford assay. Wells of a gelatin preimpregnated SDS-polyacrylamide gel (Novex, Frankfurt, Germany) were loaded with samples ( $3.75 \mu \mathrm{g}$ protein) and run for $100 \mathrm{~min}$ at $125 \mathrm{mV}$ in Tris-glycine SDS running buffer (Novex Frankfurt, Germany), during which time the bromophenol blue front reached the bottom of the gel. Positive controls included the Type I Collagenases AG770 (Chemicon International, Harrow, UK) and C-0130 (Sigma-Aldrich); the molecular weight marker SeeBlue Pre-Stained Standards (Novex) was also used. Gels were renatured in zymogram renaturing buffer (Novex) for $45 \mathrm{~min}$ and incubated overnight at $37^{\circ} \mathrm{C}$ in zymogram developing buffer (Novex). After staining with $0.5 \%$ Coomassie Blue G-250, destaining with $30 \%$ methanol, $10 \%$ acetic acid solution revealed clear bands of gelatinolytic activity. Within each assay, all samples were assessed simultaneously using the same reagents and batch of gels. Gels were digitally photographed and band densitometry assessed using a computer image analysis system (Scion Image, Frederick, Maryland, USA), to give a semiquantitative assay of enzymatic activity. Densitometry of each band was assessed blind to the diagnostic group three times and the mean score used for statistical analysis. The semiquantitative nature of this protocol was validated by densitometric analysis of serial dilutions of the two samples with the strongest bands. Assays were repeated for all samples and the results obtained for different runs were correlated. Three samples were run in each gel as internal positive controls. All gels were run under identical conditions with the same batch of reagents and densitometry results standardised between gels.

\section{Statistics}

Gelatin zymography was performed and results analysed prospectively. Statistical analysis was performed using the SPSS software system (SPSS for Windows Version 9.0, SPSS Inc., Chicago, USA). Differences in densitometry readings between groups were assessed with the Mann-Whitney $U$ and Kruskal-Wallis tests, where appropriate. Cancer-specific survival curves were estimated using the Kaplan-Meier method and the log-rank test was used to assess the statistical significance of differences between groups. A Cox proportional hazards regression model (Cox, 1972) was used to identify the impact of prognostic factors on survival and estimate hazard ratios and 95\% confidence intervals (CIs). The assumption of proportional hazards was assessed graphically by plotting $\log [-\log ($ survivor $)]$ against $\log$ (time) for each group. Prognostic variables identified by univariate analysis, with $P<0.1$, were analysed in multivariate Cox models. A forward, stepwise selection procedure was used, with variables being added to the model according to a partial likelihood ratio test, using an entry criterion of $P<0.05$.

\section{RESULTS}

\section{Patients}

Overall median survival in the MM group was 7.5 months. Six months and 1 year survival rates were 66 and $34 \%$ respectively. The definitive surgical procedures performed were radical surgery in 14 patients (11 extrapleural pneumonectomies and three radical decortications), palliative debulking surgery (Martin-Ucar et al, 2001 ) in 16 and biopsy alone in five patients. Although patients who underwent radical surgery survived longer than those who did not $(P=0.04, \log$ rank $)$, the surgical procedure performed was not an independent factor in subsequent multivariate analyses.

Three patients $(8.6 \%)$ died within 30 days of surgical biopsy. Two patients developed postoperative respiratory failure and died on days 11 and 23, while a third suffered a cardiac arrest following an acute intrathoracic haemorrhage on day 10 . These three patients were excluded from subsequent survival analyses.

\section{Gelatin zymography}

Methods validation Serial dilution of the two strongest MM samples (between 1 and $30 \mu \mathrm{g}$ ) demonstrated that at protein loads of greater than $10 \mu \mathrm{g}$ per well, the densitometry values reached a plateau (data not shown). The relation of protein load to densitometry value was linear up to and including $10 \mu \mathrm{g}$ protein per well, which was that used in the main experiments. When samples were run on different days and the correlation between them assessed, correlation coefficients of $0.936,0.863,0.973$ and 0.946 were obtained for pro-, active MMP-9, pro- and active MMP2 bands, respectively $(P<0.0001)$. The variation between gels of the control samples was minimal (data not shown).

\section{Gelatin zymography results}

Initially, $22 \mathrm{MM}$ samples were compared with the UP and IP specimens. Densitometry readings for each group and MannWhitney $P$ values are shown in Table 1 . Subsequently, the gelatin 
Table I Zymogram densitometry values in MM and benign pleura

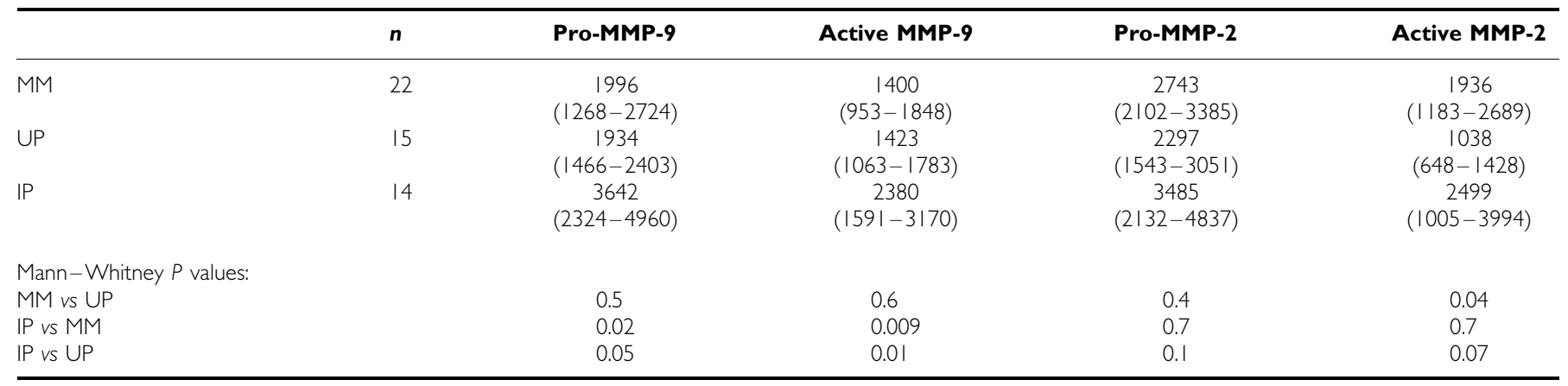

Data are displayed as mean arbitrary densitometry units $(95 \% \mathrm{Cl})$. $\mathrm{MM}=$ malignant mesothelioma; $\mathrm{UP}=$ uninflammed pleura; $\mathrm{IP}=$ inflammed pleura; $\mathrm{MMP}-9=$ gelatinase $\mathrm{B}$; MMP-2 = gelatinase $\mathrm{A}$.

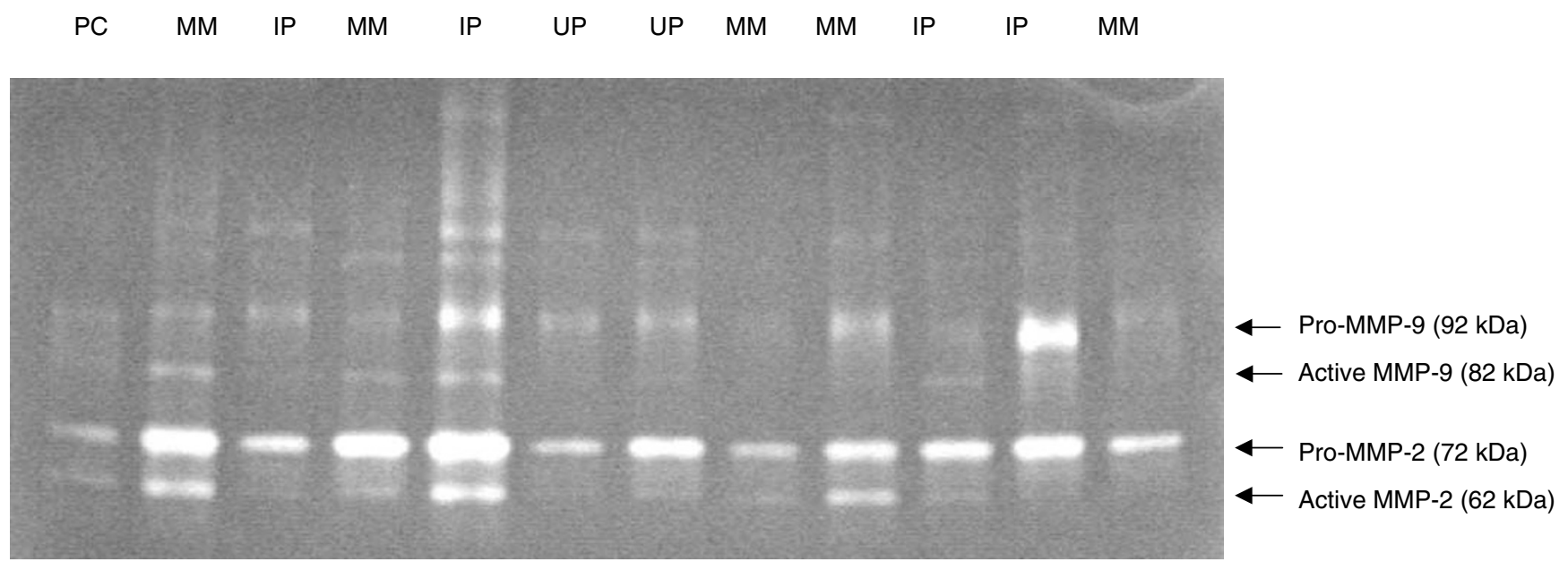

Figure I Gelatin zymogram of malignant mesothelioma (MM), inflamed pleura (IP) and uninflamed pleura (UP). Snap-frozen samples were homogenised and the supernatant proteins resolved in a gelatin preimpregnated polyacrylamide gel. Gels were developed to show clear bands of gelatinolysis, correlating with the latent, pro- and active isoforms of MMP-2 and -9.

zymography was repeated in a larger series of $35 \mathrm{MM}$ samples alone. The latter group was used to examine correlations with clinicopathological factors and survival.

Gelatinolytic bands corresponding to pro-MMP-9 and pro- and active MMP-2 were seen in all 35 cases of MM. No detectable active MMP-9 was seen in nine of the 35 MM cases (26\%). MMP-2 was the predominant gelatinase seen in MM (Figure 1). Among the 35 MM cases, pro-MMP-2 and -9 levels were mean 2600 (95\% CI $2130-3070)$ and $1640(960-2330)$ respectively $(P=0.006)$. Values were $1540(1300-1770)$ and $850(580-1110)$ for the active isoforms $(P<0.001)$. It was possible to determine densitometry values for all gelatinase isoforms in each of the UP and IP cases (Table 1).

\section{Correlation with clinicopathological variables}

Active MMP-2 was significantly elevated in MM compared with UP specimens $(P=0.04$, Table 1, Figure 2). There were no differences between MM and UP groups with regard to MMP-9 activity. There was significantly greater pro- and active MMP-9 gelatinolytic activity in IP specimens compared to the UP $(P=0.05,0.01$ respectively) and $\mathrm{MM}(P=0.02,0.009$ respectively) groups. There was no significant difference in pro- and active MMP-2 gelatinolytic activity between IP and either MM or UP specimens.

Preoperative white cell count was associated with greater total MMP-9 (sum of pro- and active MMP-9, $P=0.0006$ ) and a trend towards a similar result was seen with thrombocytosis $(P=0.06)$.
There were no significant correlations between gelatinases and gender, age, presence of chest pain or weight loss, cell type or performance status. There was no correlation between any MMP isoform and either the EORTC or CALGB prognostic scores. Pathological staging was performed only for the 13 patients who underwent radical surgery. Nodal stage was N0 in seven, N1 in one and N2 in five patients. Pro-, active and total MMP-2 activities were greater in those with extrapleural nodal metastasis than without (Table 2). There were no associations seen between gelatinases and pathological T or overall IMIG TNM stages.

\section{Correlation with survival}

In univariate Cox proportional hazards analysis, trends towards increasing pro- and total MMP-2 activities (as continuous variables) and poor prognosis were seen $(P=0.08, \mathrm{HR} 1.0003$, $95 \%$ CI $1.0000-1.0006$ and $P=0.08$, HR $1.0002,95 \%$ CI $1.0000-$ 1.0005 respectively, Figure 3). However, although trends towards poor prognosis were seen with the categorical analyses, these did not reach statistical significance in either univariate Cox proportional hazards models ( $P=0.16$ and 0.19 respectively) or the logrank test $(P=0.15$ and 0.19$)$. There was no significant relation between poor prognosis and active MMP-2, or total, pro-, or active MMP-9. Similarly, the ratio of pro- to active MMP-2 or -9 (activation ratio) and total gelatinolytic activity (sum of all four isoforms) were not prognostic. 
A

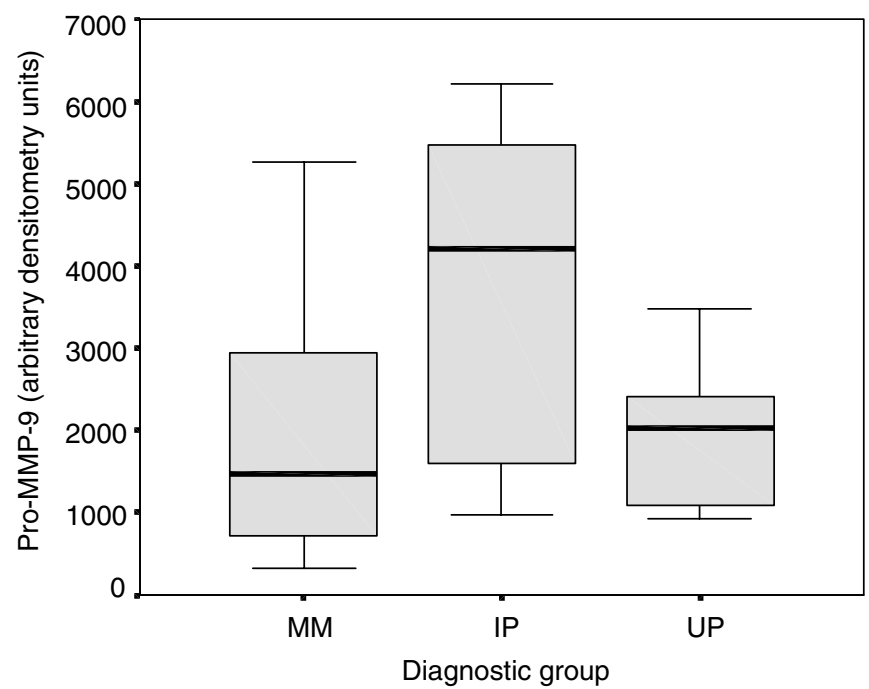

B

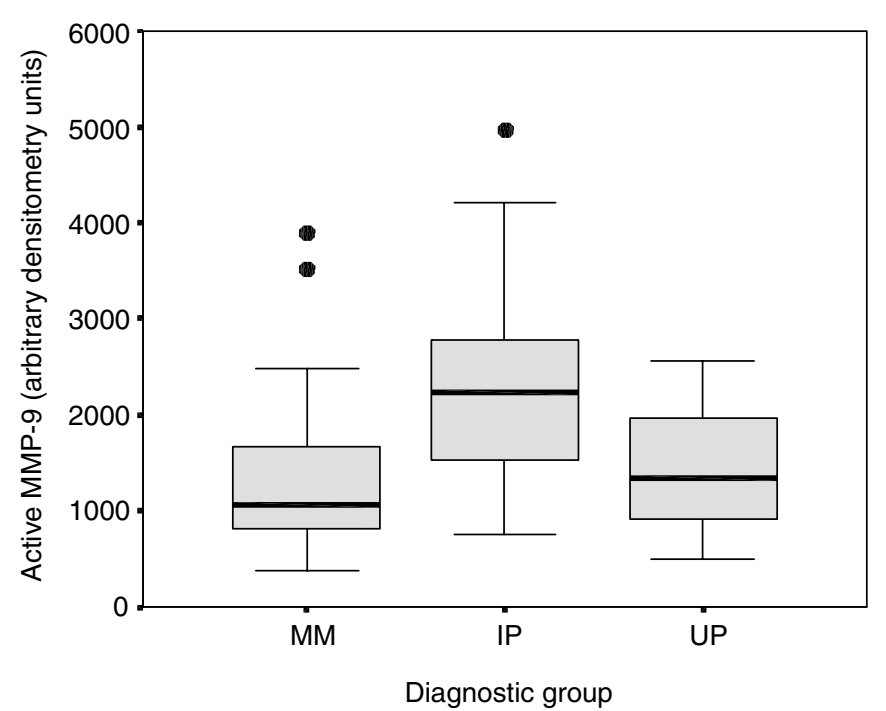

C

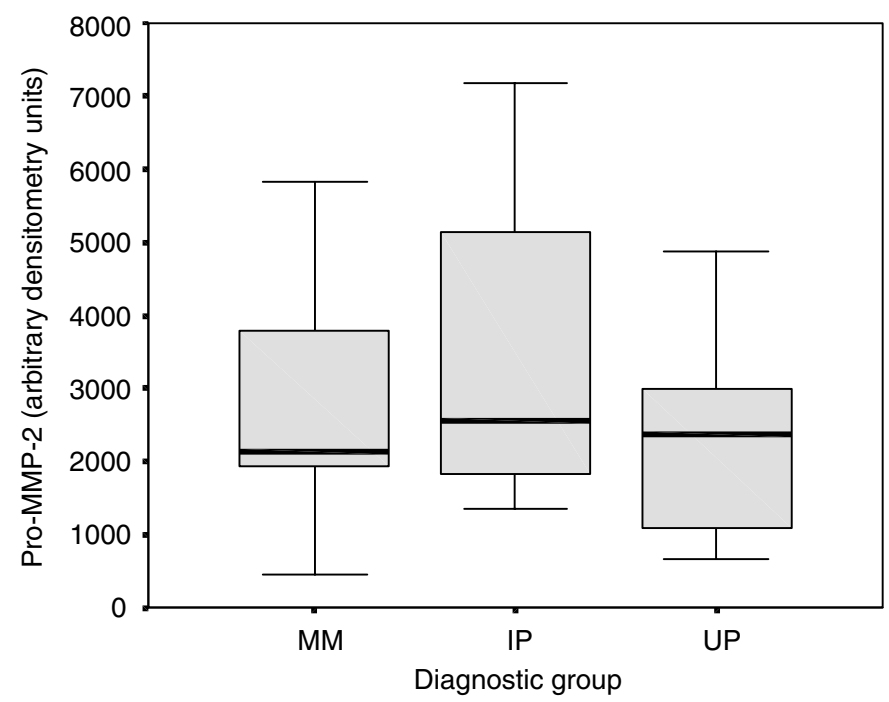

D

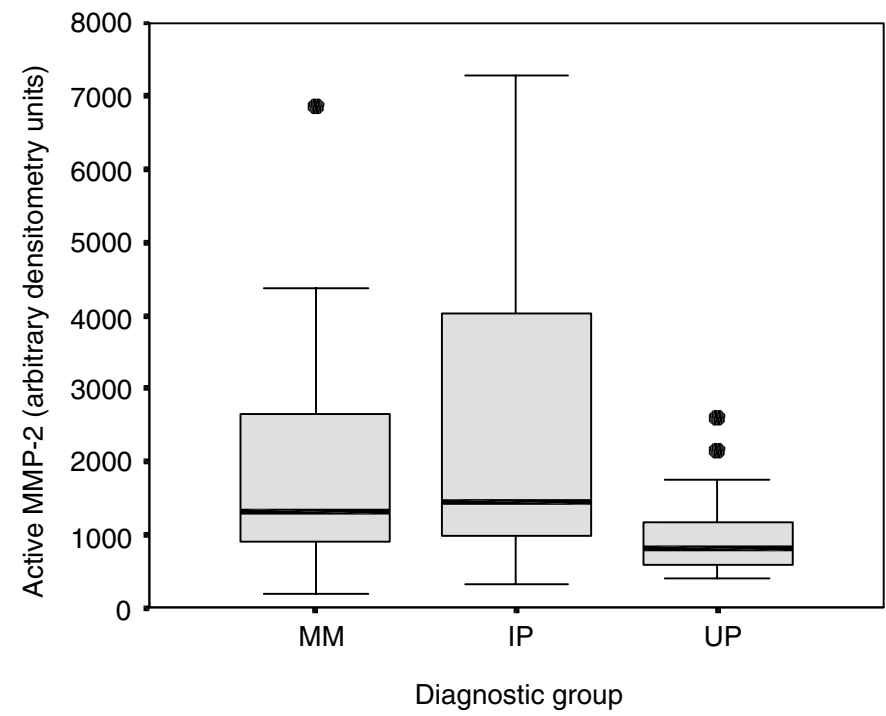

Figure 2 Boxplots showing the differences in MMP activity between MM $(n=22), U P(n=12)$ and IP $(n=15)$. Data are shown for pro-MMP-9 (A), active MMP-9 (B), pro-MMP-2 $(\mathbf{C})$ and active MMP-2 (D). Horizontal bars represent the median values, boxes the interquartile range, vertical bars the $10-$ $90 \%$ range and solid circles the outliers. MMP enzyme activity was measured with semiquantitative gelatin zymography and is expressed by arbitrary densitometry units per milligram protein.

\section{Multivariate analyses}

In addition to the association between the operation performed and survival (as outlined above), clinicopathological factors significant in univariate survival analysis were weight loss $>5 \%$ $(P=0.0006)$, nonepithelioid cell type $(P=0.0049)$ and preoperative haemoglobin $<14 \mathrm{~g} \mathrm{dl}^{-1}(P=0.03)$. These were entered with either pro-MMP-2 or total MMP-2 gelatinolytic activity into Cox proportional hazards multivariate models. Both pro-MMP-2 $(P=0.03)$ and total MMP-2 $(P=0.04)$ were independent prognostic factors in conjunction with weight loss $(P=0.0008)$, whereas the other factors entered were not. Similarly, high proMMP-2 $(P=0.04)$ and total MMP-2 $(P=0.04)$ contributed independently to the CALGB prognostic scoring system $(P=0.005$ and 0.02 respectively). The EORTC risk groups were not prognostic in univariate analysis in this series $(P=0.16, \log$ rank) and therefore were not tested in multivariate analysis.

\section{DISCUSSION}

Malignant mesothelioma is characterised by extensive local growth and invasion of intrathoracic organs. This pattern of tumour development suggests an important role for proteases, including the MMPs, in the evolution of the disease. This study demonstrates the consistent expression of active and latent forms of MMP-9 and particularly MMP-2 in MM tumour samples by gelatin zymography. We used whole tumour extracts rather than microdissected extracts since recent evidence has suggested that stromal expression of MMPs is important in tumour progression (Himelstein et al, 1994; Nawrocki et al, 1997; Polette and Birembaut, 1998; DeClerck, 2000; Kikuchi et al, 2000). Gelatin zymography was found to be reproducible, with a low variation between samples run on different days and between the control samples run in each gel. The serial dilution experiment confirmed the semiquantitative nature of the assay when $10 \mu \mathrm{g}$ protein was loaded to each well. 
Table 2 Correlation between MMP-2 and MMP-9 activities and clinicopathological variables

\begin{tabular}{|c|c|c|c|c|c|c|c|c|}
\hline Variable & & $n$ & Pro-MMP-9 & $\begin{array}{l}\text { Active } \\
\text { MMP-9 }\end{array}$ & $\begin{array}{l}\text { Total } \\
\text { MMP-9 }\end{array}$ & Pro-MMP-2 & $\begin{array}{l}\text { Active } \\
\text { MMP-2 }\end{array}$ & $\begin{array}{l}\text { Total } \\
\text { MMP-2 }\end{array}$ \\
\hline Cell type & $\begin{array}{l}\text { Epithelioid } \\
\text { Nonepithelioid } \\
P\end{array}$ & $\begin{array}{l}23 \\
12\end{array}$ & $\begin{array}{l}1176 \\
816 \\
0.082\end{array}$ & $\begin{array}{l}608 \\
633 \\
0.344\end{array}$ & $\begin{array}{l}1693 \\
1419 \\
0.237\end{array}$ & $\begin{array}{l}2104 \\
2422 \\
0.281\end{array}$ & $\begin{array}{l}1199 \\
|49| \\
0.889\end{array}$ & $\begin{array}{l}3418 \\
4087 \\
0.314\end{array}$ \\
\hline White blood cells & $\begin{array}{l}<8.3 \times 10^{9} \mathrm{I}^{-1} \\
\geqslant 8.3 \times 10^{9} \mathrm{I}^{-1} \\
P\end{array}$ & $\begin{array}{l}13 \\
22\end{array}$ & $\begin{array}{r}788 \\
\mid 167 \\
0.065\end{array}$ & $\begin{array}{l}511 \\
638 \\
0.109\end{array}$ & $\begin{array}{l}1279 \\
1796 \\
0.006\end{array}$ & $\begin{array}{l}1988 \\
2468 \\
0.585\end{array}$ & $\begin{array}{l}1193 \\
1559 \\
0.824\end{array}$ & $\begin{array}{l}3426 \\
3895 \\
0.539\end{array}$ \\
\hline Haemoglobin & $\begin{array}{l}<14 \mathrm{gdl}^{-1} \\
\geqslant 14 \mathrm{gdl}^{-1} \\
P\end{array}$ & $\begin{array}{l}22 \\
13\end{array}$ & $\begin{array}{r}824 \\
1367 \\
0.037\end{array}$ & $\begin{array}{l}629 \\
502 \\
0.158\end{array}$ & $\begin{array}{l}1412 \\
1764 \\
0.142\end{array}$ & $\begin{array}{l}2279 \\
1955 \\
0.517\end{array}$ & $\begin{array}{l}|49| \\
\mid 193 \\
0.597\end{array}$ & $\begin{array}{l}3814 \\
3012 \\
0.375\end{array}$ \\
\hline EORTC prognostic group & $\begin{array}{l}\text { Low risk } \\
\text { High risk } \\
P\end{array}$ & $\begin{array}{l}20 \\
15\end{array}$ & $\begin{array}{r}895 \\
1157 \\
0.463\end{array}$ & $\begin{array}{l}611 \\
608 \\
0.534\end{array}$ & $\begin{array}{l}1448 \\
1764 \\
0.217\end{array}$ & $\begin{array}{l}2279 \\
2092 \\
0.714\end{array}$ & $\begin{array}{l}1440 \\
\mid 199 \\
0.84 \mid\end{array}$ & $\begin{array}{l}3547 \\
4018 \\
0.790\end{array}$ \\
\hline IMIG nodal status & $\begin{array}{l}\mathrm{N} 0, \mathrm{NI} \\
\mathrm{N} 2 \\
P\end{array}$ & $\begin{array}{l}8 \\
5\end{array}$ & $\begin{array}{l}109 \mid \\
1042 \\
0.884\end{array}$ & $\begin{array}{l}189 \\
662 \\
0.075\end{array}$ & $\begin{array}{l}1353 \\
1727 \\
0.107\end{array}$ & $\begin{array}{l}1093 \\
3643 \\
0.019\end{array}$ & $\begin{array}{l}1086 \\
1852 \\
0.013\end{array}$ & $\begin{array}{l}3069 \\
6097 \\
0.008\end{array}$ \\
\hline IMIG stage & $\begin{array}{l}\| \\
\text { III } \\
\text { IV } \\
P\end{array}$ & $\begin{array}{r}2 \\
11 \\
8\end{array}$ & $\begin{array}{r}962 \\
1043 \\
1000 \\
0.840\end{array}$ & $\begin{array}{l}383 \\
625 \\
409 \\
0.689\end{array}$ & $\begin{array}{c}1345 \\
1483 \\
1437 \\
0.755\end{array}$ & $\begin{array}{l}1566 \\
2847 \\
1923 \\
0.173\end{array}$ & $\begin{array}{c}1317 \\
1725 \\
1184 \\
0.797\end{array}$ & $\begin{array}{l}2883 \\
4677 \\
3207 \\
0.353\end{array}$ \\
\hline
\end{tabular}

The median densitometry value for each isoform is quoted. The Mann - Whitney U-test was used for the comparison of two groups and the Kruskal -Wallis Test for greater than two groups. Total MMP activity equals the sum of pro- and active enzyme values. MMP-9= gelatinase B; MMP-2 = gelatinase A; CALGB=Cancer and Leukemia Group B; EORTC = European Organisation for Research and Treatment of Cancer; IMIG = International Mesothelioma Interest Group.

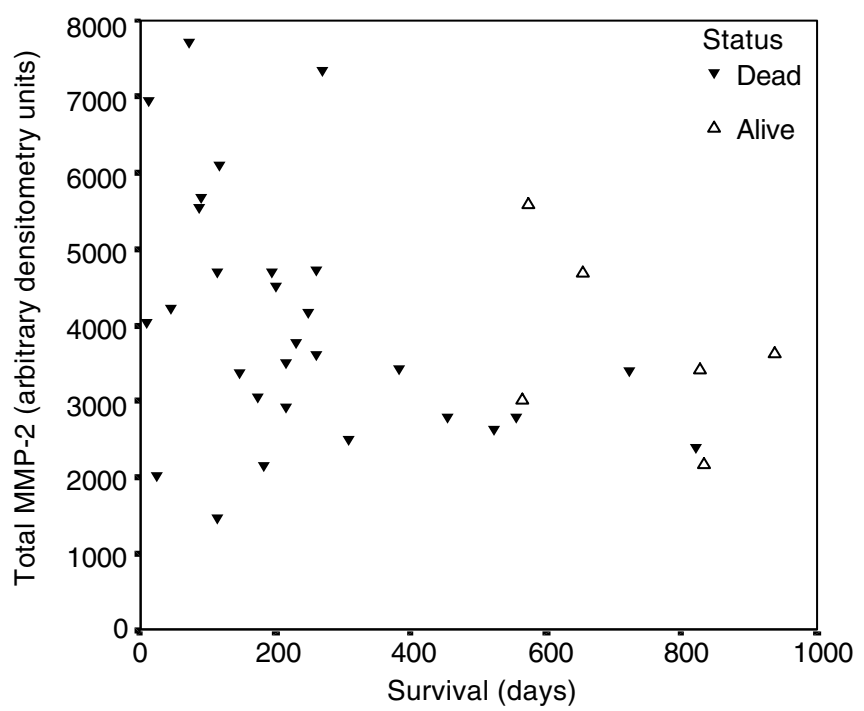

Figure 3 Scatterplot showing the relation between survival and total MMP-2 activity (sum of pro-MMP-2 and active MMP-2 band arbitrary densitometry units). There was a trend towards worse survival in patients with increasing values ( $P=0.08$, Cox proportional hazards).

The benign UP control group specimens were obtained from patients undergoing pleurectomy for primary spontaneous pneumothorax. However, even this group may not display true baseline expression of MMPs. Both acute and chronic inflammatory changes were noted in the histopathology reports of the diagnostic tissue blocks from the 'UP' specimens that accompanied the snapfrozen samples used in this study. It is possible to speculate, therefore, that we have underestimated the degree of upregulation of MMPs in MM, and indeed in IP, compared to UP.

The patterns of gelatinolytic activity seen in MM, IP and UP are likely to reflect both the nature and extent of the inflammatory cell infiltrate in these conditions, and between benign and malignant mesothelial cells. The predominant gelatinase expressed by macrophages and neutrophils in inflammatory conditions such as emphysema, asthma, sepsis and inflammatory bowel disease is MMP-9 (Finlay et al, 1997; Mautino et al, 1997; Pugin et al, 1999), which is in keeping with the significantly elevated activity of this enzyme seen in IP specimens compared to either MM or UP samples. Furthermore, the observation that total MMP-9 was significantly greater in MM patients with a WCC greater than $8.3 \times 10^{9} 1^{-1}$ supports this contention. The levels of active MMP-2 were found in this study to be significantly higher in MM than UP. This finding suggests that the MMP-2 activity seen in MM may be more specific than MMP-9 to the carcinogenic process.

Activities of MMP-2 and -9 isoforms have been investigated by gelatin zymography in other solid tumours. Upregulation of MMP-2 is seen in solid tumours including hepatocellular (Maatta et al, 2000), colorectal (Liabakk et al, 1996; Baker et al, 2000; Waas et al, 2002) and ovarian cancers (Lengyel et al, 2001). With regard to the relation of MMP activity, as assessed by gelatin zymography, with prognosis, results differ between studies and tumour types. In oral squamous cell carcinoma, activities of MMP-2 and -9 correlate 
with disease-free survival (Yorioka et al, 2002). In colorectal cancer, the relations between MMP activities and tumour progression remain unclear. Waas et al (2002) found no association between MMP activity and nodal metastasis, but did note significantly lower tumour extract MMP-2 activity in patients with distant metastasis. Baker found that total MMP-2 and -9 levels in colorectal tumour samples, as assessed by gelatinase activity assays, correlated positively with Dukes' stages (Baker and Leaper, 2002). Liabakk, however, demonstrated higher levels of MMP-9 in Dukes' stages A and C (Liabakk et al, 1996). Brown found that active MMP-2 correlated with stage in NSCLC (Brown et al, 1993b) but not breast cancer (Brown et al, 1993a). Pro-MMP-9, but neither MMP-2 isoform, was associated with poor survival in both univariate and multivariate analyses in ovarian cancer (Lengyel et al, 2001). No relations were seen in bladder cancer (Papathoma et al, 2000), hepatocellular carcinoma (Maatta et al, 2000) or softtissue sarcomas (Maguire et al, 2000).

The numbers in our study are relatively small, particularly with respect to those with an accurate pathological TNM stage. The accuracy of radiological TNM staging in MM remains unclear and therefore we made no attempt to assess the stage of patients who did not undergo radical surgery and detailed pathological assessment. Nonetheless, the positive correlation between MMP-2 activity and nodal status noted here is in keeping with a number of studies in other tumours cited above. Similarly, although our multivariate survival analyses may lack high statistical rigour, our results are provocative and justify confirmatory studies in a larger series of patients.

The regulation of MMP expression (Jones and Walker, 1997) in MM remains to be characterised. Nonetheless, many growth factors known to induce MMP expression are detectable in MM. These include basic fibroblast growth factor (bFGF) (Kumar-Singh et al, 1999), hepatocyte growth factor/scatter factor (Tolnay et al, 1998), vascular endothelial growth factor (VEGF) (Ohta et al, 1999), insulin-like growth factor (IGF)-1, tumour necrosis factor

\section{REFERENCES}

Abiru S, Nakao K, Ichikawa T, Migita K, Shigeno M, Sakamoto M, Ishikawa H, Hamasaki K, Nakata K, Eguchi K (2002) Aspirin and NS-398 inhibit hepatocyte growth factor-induced invasiveness of human hepatoma cells. Hepatology 35: $1117-1124$

Antony VB, Hott JW, Godbey SW, Holm K (1996) Angiogenesis in mesotheliomas. Role of mesothelial cell derived IL-8. Chest 109: 21S -22S

Attiga FA, Fernandez PM, Weeraratna AT, Manyak MJ, Patierno SR (2000) Inhibitors of prostaglandin synthesis inhibit human prostate tumor cell invasiveness and reduce the release of matrix metalloproteinases. Cancer Res 60: 4629-4637

Baker EA, Bergin FG, Leaper DJ (2000) Matrix metalloproteinases, their tissue inhibitors and colorectal cancer staging. $\mathrm{Br} J$ Surg 87: $1215-1221$

Baker EA, Leaper DJ (2002) Measuring gelatinase activity in colorectal cancer. Eur J Surg Oncol 28: 24-29

Bielefeldt-Ohmann H, Jarnick A, Fitzpatrick D (1996) Molecular pathobiology and immunology of malignant mesothelioma. J Pathol 178: $369-378$

Bissett D, O’Byrne KJ, von Pawel J, Mercier R, Price A, Nicholson M, Shepherd F, Mazabel E, Penning C, Zhang MH, Collier MA (2002) Phase III study of the matrix metalloproteinase (MMP) inhibitor prinomastat $(P)$ in combination with gemcitabine $(G)$ and cisplatin $(C)$ in non-small cell lung cancer. Proc ASCO 21: 296a

Bramhall SR, Hallissey MT, Whiting J, Scholefield J, Tierney G, Stuart RC, Hawkins RE, McCulloch P, Maughan T, Brown PD, Baillet M, Fielding JW (2002a) Marimastat as maintenance therapy for patients with advanced gastric cancer: a randomised trial. Br J Cancer 86: 1864-1870

Bramhall SR, Schulz J, Nemunaitis J, Brown PD, Baillet M, Buckels JA (2002b) A double-blind placebo-controlled, randomised study comparing gemcitabine and marimastat with gemcitabine and placebo as first line therapy in patients with advanced pancreatic cancer. Br J Cancer 87: $161-167$
(TNF), transforming growth factors- $\alpha$ and $-\beta$ (Bielefeldt-Ohmann et al, 1996) and interleukin-8 (Antony et al, 1996). The interrelation between these growth factors and MMP expression in MM tumour samples needs to be investigated. Furthermore, gelatin zymography does not discriminate between free MMPs and those complexed with TIMPs, mRNA for which have been identified in MM cells in vitro (Liu et al, 2001). Further study is required to address the balance of MMPs with respect to TIMPs in MM tumour samples.

The detection of active gelatinase isoforms in MM samples, particularly MMP-2, is important and suggests that MMP inhibitors may be therapeutic in this disease. Evidence to support this contention comes from both experimental and clinical studies. Inhibition of MMPs reduces tumour growth, invasion and angiogenesis in vivo (Maekawa et al, 1999). Initial phase III trials of MMP inhibitors in other solid tumours alone or in combination with cytotoxic agents have overall been disappointing (Bissett et al, 2002; Bramhall et al, 2002a, b). Nonetheless, inhibition of MMP activity, with synthetic MMP inhibitors (Drummond et al, 1999; Steward, 1999) or with biological agents that downregulate the synthesis and activation of the enzymes such as the selective COX2 inhibitors (Reich and Martin, 1996; Attiga et al, 2000; Pan et al, 2001; Abiru et al, 2002), deserves clinical investigation as a novel approach to the management of MM.

\section{ACKNOWLEDGEMENTS}

This work was supported by the Institute of Cancer Studies and Institute for Lung Health, Leicester, UK. JGE was funded by a Leicester Royal Infirmary Research Fellowship. We also extend our gratitude to the June Hancock Memorial Fund and Sir Samuel Scott of Yews Trust for their financial support of this project.
Brown PD, Bloxidge RE, Anderson E, Howell A (1993a) Expression of activated gelatinase in human invasive breast carcinoma. Clin Exp Metastasis 11: $183-189$

Brown PD, Bloxidge RE, Stuart NS, Gatter KC, Carmichael J (1993b) Association between expression of activated 72-kilodalton gelatinase and tumor spread in non-small-cell lung carcinoma. J Natl Cancer Inst 85: $574-578$

Cox D (1972) Regression models and life tables. J Roy Stat Soc 34: 187-220

Cox G, Jones JL, Andi A, Waller DA, O'Byrne KJ (2000a) Molecular biological staging system for operable non-small cell lung cancer. Thorax 56: $561-566$

Cox G, Jones JL, O’Byrne KJ (2000b) Matrix metalloproteinase 9 and the epidermal growth factor signal pathway in operable non-small cell lung cancer. Clin Cancer Res 6: 2349-2355

Cox G, Steward W, O'Byrne K (1999) The plasmin cascade and matrix metalloproteinases in non-small cell lung cancer. Thorax 54: $169-179$

Cox G, Walker RA, Andi A, Steward WP, O’Byrne KJ (2000c) Prognostic significance of platelet and microvessel counts in operable non-small cell lung cancer. Lung Cancer 29: $169-177$

Curran D, Sahmoud T, Therasse P, Van Meerbeeck J, Postmus PE, Giaccone G (1998) Prognostic factors in patients with pleural mesothelioma: the European Organisation for Research and Treatment of Cancer Experience. J Clin Oncol 16: 145-152

DeClerck YA (2000) Interactions between tumour cells and stromal cells and proteolytic modification of the extracellular matrix by metalloproteinases in cancer. Eur J Cancer 36: 1258-1268

Di Nezza LA, Misajon A, Zhang J, Jobling T, Quinn MA, Ostor AG Nie G, Lopata A, Salamonsen LA (2002) Presence of active gelatinases in endometrial carcinoma and matrix metalloproteinase expression with increasing tumor grade and invasion. Cancer 94: $1466-1475$ 
Dickinson AJ, Fox SB, Persad RA, Hollyer J, Sibley GN, Harris AL (1994) Quantification of angiogenesis as an independent predictor of prognosis in invasive bladder carcinomas. Br J Urol 74: 762 - 766

Drummond AH, Beckett P, Brown PD, Bone EA, Davidson AH, Galloway WA, Gearing AJ, Huxley P, Laber D, McCourt M, Whittaker M, Wood LM, Wright A (1999) Preclinical and clinical studies of MMP inhibitors in cancer. Ann NY Acad Sci 878: 228-235

Edwards J, Cox G, Andi A, Jones J, Walker R, Waller D, O'Byrne K (2001) Angiogenesis is an independent prognostic factor in malignant mesothelioma. Br J Cancer 85: 865-868

Edwards JG, Abrams KR, Leverment JN, Spyt TJ, Waller DA, O'Byrne KJ (2000) Prognostic factors for malignant mesothelioma in 142 patients: validation of CALGB and EORTC prognostic scoring systems. Thorax 55: $731-735$

Finlay GA, O'Driscoll LR, Russell KJ, D'Arcy EM, Masterson JB, FitzGerald MX, O'Connor CM (1997) Matrix metalloproteinase expression and production by alveolar macrophages in emphysema. Am J Resp Crit Care Med 156: $240-247$

Fox SB, Leek RD, Smith K, Hollyer J, Greenall M, Harris AL (1994) Tumor angiogenesis in node-negative breast carcinomas-relationship with epidermal growth factor receptor, estrogen receptor, and survival. Breast Cancer Res Treat 29: 109-116

Harvey P, Clark IM, Jaurand MC, Warn RM, Edwards DR (2000) Hepatocyte growth factor/scatter factor enhances the invasion of mesothelioma cell lines and the expression of matrix metalloproteinases. Br J Cancer 83: $1147-1153$

Herndon JE, Green MR, Chahinian AP, Corson JM, Suzuki Y, Vogelzang NJ (1998) Factors predictive of survival among 337 patients with mesothelioma treated between 1984 and 1994 by the Cancer and Leukemia Group B. Chest 113: 723-731

Himelstein BP, Canete-Soler R, Bernhard EJ, Dilks DW, Muschel RJ (1994) Metalloproteinases in tumor progression: the contribution of MMP-9. Invasion Metastasis 14: 246-258

Ikebe T, Shinohara M, Takeuchi H, Beppu M, Kurahara S, Nakamura S, Shirasuna K (1999) Gelatinolytic activity of matrix metalloproteinase in tumor tissues correlates with the invasiveness of oral cancer. Clin Exp Metastasis 17: $315-323$

Jones JL, Walker RA (1997) Control of matrix metalloproteinase activity in cancer. J Pathol 183: 377-379

Karakiulakis G, Papanikolaou C, Jankovic SM, Aletras A, Papakonstantinou E, Vretou E, Mirtsou-Fidani V (1997) Increased type IV collagendegrading activity in metastases originating from primary tumors of the human colon. Invasion Metastasis 17: 158-168

Kikuchi R, Noguchi T, Takeno S, Kubo N, Uchida Y (2000) Immunohistochemical detection of membrane-type-1-matrix metalloproteinase in colorectal carcinoma. Br J Cancer 83: 215-218

Kumar-Singh S, Vermeulen PB, Weyler J, Segers K, Weyn B, Van Daele A, Dirix LY, Van Oosterom AT, Van Marck E (1997) Evaluation of tumour angiogenesis as a prognostic marker in malignant mesothelioma. J Pathol 182: $211-216$

Kumar-Singh S, Weyler J, Martin MJ, Vermeulen PB, Van Marck E (1999) Angiogenic cytokines in mesothelioma: a study of VEGF, FGF-1 and -2, and TGF beta expression. J Pathol 189: $72-78$

Lengyel E, Schmalfeldt B, Konik E, Spathe K, Harting K, Fenn A, Berger U, Fridman R, Schmitt M, Prechtel D, Kuhn W (2001) Expression of latent matrix metalloproteinase 9 (MMP-9) predicts survival in advanced ovarian cancer. Gynecol Oncol 82: 291-298

Liabakk NB, Talbot I, Smith RA, Wilkinson K, Balkwill F (1996) Matrix metalloprotease 2 (MMP-2) and matrix metalloprotease 9 (MMP-9) type IV collagenases in colorectal cancer. Cancer Res 56: 190-196

Liu Z, Ivanoff A, Klominek J (2001) Expression and activity of matrix metalloproteases in human malignant mesothelioma cell lines. Int $J$ Cancer 91: 638-643

Maatta M, Soini Y, Liakka A, Autio-Harmainen H (2000) Differential expression of matrix metalloproteinase (MMP)-2, MMP-9, and membrane type 1-MMP in hepatocellular and pancreatic adenocarcinoma: implications for tumor progression and clinical prognosis. Clin Cancer Res 6: $2726-2734$

Maekawa R, Maki H, Yoshida H, Hojo K, Tanaka H, Wada T, Uchida N, Takeda Y, Kasai H, Okamoto H, Tsuzuki H, Kambayashi Y, Watanabe F, Kawada K, Toda K, Ohtani M, Sugita K, Yoshioka T (1999) Correlation of antiangiogenic and antitumor efficacy of N-biphenyl sulfonyl-phenylalanine hydroxiamic acid (BPHA), an orallyactive, selective matrix metalloproteinase inhibitor. Cancer Res 59: $1231-1235$
Maguire PD, Qi W, Lallemand R, Scully SP (2000) Gelatinase and inhibitor expression in soft tissue sarcomas: lack of correlation with distant metastasis. Oncology 59: 139-144

Martin-Ucar AE, Edwards JG, Rengarajan A, Muller S, Waller DA (2001) Palliative debulking surgery in malignant mesothelioma. Predictors of survival and symptom control. Eur J Cardiothorac Surg 20: 1117-1121

Mautino G, Oliver N, Chanez P, Bousquet J, Capony F (1997) Increased release of matrix metalloproteinase-9 in bronchoalveolar lavage fluid and by alveolar macrophages of asthmatics. Am J Resp Cell Molec Biol 17: $583-591$

Nawrocki B, Polette M, Marchand V, Monteau M, Gillery P, Tournier JM, Birembaut P (1997) Expression of matrix metalloproteinases and their inhibitors in human bronchopulmonary carcinomas: quantificative and morphological analyses. Int J Cancer 72: 556-564

O’Byrne KJ, Cox G, Swinson D, Richardson D, Edwards JG, Lolljee J, Andi A, Koukourakis MI, Giatromanolaki A, Gatter K, Harris AL, Waller D, Jones JL (2001) Towards a biological staging model for operable non-small cell lung cancer. Lung Cancer 34 (suppl 2): S83-S89

Ohta Y, Shridhar V, Bright RK, Kalemkerian GP, Du W, Carbone M, Watanabe Y, Pass HI (1999) VEGF and VEGF type C play an important role in angiogenesis and lymphangiogenesis in human malignant mesothelioma tumours. Br J Cancer 81: 54-61

Pan MR, Chuang LY, Hung WC (2001) Non-steroidal anti-inflammatory drugs inhibit matrix metalloproteinase-2 expression via repression of transcription in lung cancer cells. FEBS Lett 508: $365-368$

Papathoma AS, Petraki C, Grigorakis A, Papakonstantinou H, Karavana V, Stefanakis S, Sotsiou F, Pintzas A (2000) Prognostic significance of matrix metalloproteinases 2 and 9 in bladder cancer. Anticancer Res 20: 2009-2013

Polette M, Birembaut P (1998) Membrane-type metalloproteinases in tumor invasion. Int J Biochem Cell Biol 30: 1195-1202

Pugin J, Widmer MC, Kossodo S, Liang CM, Preas HL, Suffredini AF (1999) Human neutrophils secrete gelatinase $\mathrm{B}$ in vitro and in vivo in response to endotoxin and proinflammatory mediators. Am J Resp Cell Mol Biol 20: $458-464$

Reich R, Martin GR (1996) Identification of arachidonic acid pathways required for the invasive and metastatic activity of malignant tumor cells. Prostaglandins 51: $1-17$

Rusch V (1995) A proposed new international TNM staging system for malignant pleural mesothelioma. Chest 108: $1122-1128$

Rusch VW, Piantadosi S, Holmes EC (1991) The role of extrapleural pneumonectomy in malignant mesothelioma: a Lung Cancer Study Group trial. $J$ Thorac Cardiovasc Surg 102: 1 -9

Schwartz GK (1996) Invasion and metastases in gastric cancer: in vitro and in vivo models with clinical correlations. Semin Oncol 23: 316-324

Sterman DH, Kaiser LR, Albelda SM (1999) Advances in the treatment of malignant pleural mesothelioma. Chest 116: 504-520

Steward W (1999) Marimastat (BB2516): current status of development. Cancer Chemother Pharmacol 43 (Suppl): S56-S60

Sugarbaker DJ, Flores RM, Jaklitsch MT, Richards WG, Strauss GM, Corson JM, DeCamp Jr MM, Swanson SJ, Bueno R, Lukanich JM, Baldini EH, Mentzer SJ (1999) Resection margins, extrapleural nodal status, and cell type determine postoperative long-term survival in trimodality therapy of malignant pleural mesothelioma: results in 183 patients. J Thorac Cardiovasc Surg 117: 54-63

Sugarbaker DJ, Norberto JJ (1998) Multimodality management of malignant pleural mesothelioma. Chest 113: 61S-65S

Tokuraku M, Sato H, Murakami S, Okada Y, Watanabe Y, Seiki M (1995) Activation of the precursor of gelatinase $\mathrm{A} / 72 \mathrm{kDa}$ type IV collagenase/ MMP-2 in lung carcinomas correlates with the expression of membranetype matrix metalloproteinase (MT-MMP) and with lymph node metastasis. Int J Cancer 64: 355-359

Tolnay E, Kuhnen C, Wiethege T, Konig JE, Voss B, Muller KM (1998) Hepatocyte growth factor/scatter factor and its receptor c-Met are overexpressed and associated with an increased microvessel density in malignant pleural mesothelioma. J Cancer Res Clin Oncol 124: $291-296$

Waas ET, Lomme RM, DeGroot J, Wobbes T, Hendriks T (2002) Tissue levels of active matrix metalloproteinase- 2 and -9 in colorectal cancer. $\mathrm{Br}$ J Cancer 86: 1876-1883

Yorioka CW, Coletta RD, Alves F, Nishimoto IN, Kowalski LP, Graner E (2002) Matrix metalloproteinase-2 and -9 activities correlate with the disease-free survival of oral squamous cell carcinoma patients. Int $J$ Oncol 20: $189-194$ 